\title{
Consumer Choice, Firm Performance and Channel Coordination in a Dual-Channel Distribution System
}

\author{
Wei Song, Renwen Wang, Yelin Fu, Xiaobao Peng \\ University of Science and Technology of China, Hefei, China \\ Email: rwwang@mail.ustc.edu.cn
}

Received 13 May 2014; revised 15 June 2014; accepted 28 June 2014

Copyright $@ 2014$ by authors and Scientific Research Publishing Inc.

This work is licensed under the Creative Commons Attribution International License (CC BY).

http://creativecommons.org/licenses/by/4.0/

(c) (i) Open Access

\begin{abstract}
The expanding role of the Internet in consumer purchasing activities has created substantial new opportunities accessing to end-consumers. More and more manufacturers are beginning to sell products to potential consumers directly online while continuing to sell through the traditional brick-and-mortar retailers, a phenomenon leading to intense channel competition and conflicts. Using game theory, this research examines the effect of market segments, consumer choice and the acceptance of direct online channels on firm performance and the whole system's profit. The analysis indicates that the addition of direct online channel does not necessarily harm the incumbent retailers. A win-win zone is proposed, in which both the manufacturer and the retailer benefit from the encroachment.
\end{abstract}

Keywords

Dual-Channel, Encroachment, Consumer Choice, Win-Win Zone, Game Theory, Channel Coordination

\section{Introduction}

Several substantial industry reports have been released demonstrating that there has been rapid expansion of electronic business channels [1]. For instance, according to new statistical data from ComScore Networks, US online retail spending reached a record $\$ 56.781$ billion in Q4-2012(the $4^{\text {th }}$ quarter of 2012). This figure is up $14 \%$ from \$49.698 billion in Q4-2011 and 35\% from \$41.936 billion in Q3-2012 (www.prnewswire.com). In addition, Forrester and Shop.org estimate that more than 400,000 individuals are employed by e-Commerce companies in the US and that figure will reach 500,000 by 2017. Also, Forrester Research has forecast that online business in 
USA would surge to $\$ 370$ billion in 2017. In comparison, European online retail sales will hit $€ 191$ billion by 2017, up from $€ 128$ billion in 2013 (www.forrester.com). With the attractive growth rate of e-business and the rapid development of materials delivery by third-party logistics companies, such as Federal Express and United Parcel Services, thousands of manufacturers, such as IBM, Cisco Systems, Nike, Estee Lauder and Mattel, in different industry segments, have begun to sell products to potential consumers directly online while continuing to sell through the traditional brick-and-mortar retailers (Tsay and Agrawal [2]; Berger [3]; Yan [4] [5]).

The prevailing tendency of mixed distribution channels is significantly changing the historical relationship between manufacturer and retailers. A manufacturer can reduce or even eliminate its reliance on reseller intermediaries, gaining better visibility in market (Lee et al. [6]). Therefore, a manufacturer may be able to reach and sell to target consumers at a higher margin through direct online channels (Kumar and Ruan, [7]). However, on the other hand, conventional wisdom is that incumbent retailers would suffer from their manufacturers' encroachment on their operations by way of selling directly to final consumers. Furthermore, the addition of direct online channels not only makes traditional retailers feel disenfranchised, thus making them react adversely, but also gives rise to much fiercer competition. Consequently, both the manufacturer and the retailer are engaged in horizontal and vertical competition simultaneously, inevitably leading to channel conflicts.

Generally speaking, attempts to develop cooperative relationship between the manufacturer and the retailer can be significantly undermined by channel conflicts, which definitely have a negative effect on both parties' profits. Despite the exponential growth and the huge potential of direct online marketing channels, finding the best way to integrate them with traditional brick-and-mortar reseller channels seamlessly continues to be a big challenge for many firms. For instance, Levi Strauss discontinued its online direct sales of Levi products from their own websites in 1999, due to complaints from its intermediaries who were dissatisfied with the potential competition from the direct online channel (Business [8]; San Francisco Examiner, 1999; Kumar and Ruan [7]). In contrast, there exist many manufacturers who have successfully operated their hybrid channel structures. For example, IBM's online sales were up 10.3\% year-over-year in Q4-2013, Department stores with Ecommerce platforms saw the largest growth, with a $62 \%$ increase in online sales in Q4. Homes goods retailers saw growth of $46.4 \%$, health \& beauty e-stores saw a $14.7 \%$ increase, and apparel websites saw a $10.2 \%$ increase in sales during Q4. (www.internetretailer.com).

The expanding role of the Internet in consumer and business procurement activities has not only provided the manufacturers new opportunities for direct access to end consumers, but has also motivated them to seek optimal distribution portfolios to alleviate channel conflicts. Therefore, the focal topic is how to alleviate or even eliminate channel competition and conflicts, which would definitely benefit both parties in a mixed channel context.

In our work, we investigate the conditions under which the manufacturer should open a direct online channel, given that this additional direct channel could be virtually in conflict with the incumbent retail channel. Potential consumers are segmented into two types: brand (or manufacturer) loyal and store (or retailer) loyal. Brand (or manufacturer) loyal consumers only purchase the manufacturer's brand, either from the conventional retailer or the manufacturer directly, whereas the store (or retailer) loyal customers only purchase from the retailer, overlooking the brand difference (Kumar and Ruan [7]; Cai [9]). Furthermore, for brand loyal consumers, there exist diverse acceptance levels of direct online channels. Liang conducted an empirical study and demonstrated that customers prefer traditional retail stores to direct online channels. Therefore, brand (or manufacturer) loyal consumers make their decisions of channel choice according to the corresponding consumer surplus, derived from acceptance levels of the direct online channel and price difference.

In this research, we consider a single-manufacturer-single-retailer supply chain. When the manufacturer opens a new direct online channel, potential consumers can purchase products from either the conventional retail channel or the direct online channel. We first study consumer choice to formulate linear demand functions for both channels. When then examine of the impact on profits of the manufacturer, the retailer and the whole system from adding the direct online channel and market characteristics.

Specifically, our paper addresses the following questions:

1) How does consumer choice affect system performance?

2) Based on the aforementioned consumer choice, how does the addition of a direct online channel to the conventional channel affect profits of channel members and the system?

The rest of our paper proceeds as follows. Section 2 presents a brief review of related literature. Section 3 pro- 
vides our model framework. Section 4 analyzes relative performance of the dual-channel's members and the system, and characterizes the key results. Section 5 concludes the paper and provides some managerial implications.

\section{Literature Review}

A substantial mass of research literature has studied the positive effect of the manufacturer's encroachment. Chiang [10] showed that direct marketing, on one hand, helps the manufacturer improve profit performance, and on the other hand, since it constrains the retailer's pricing behavior, it may not be detrimental to the retailer. Cattani [11] [12] analyzed three different pricing strategies after the entry of the manufacturer's online channel and the rising competition between the manufacturer and the retailer. They found that equal-pricing strategy not only optimizes the manufacturer's profit, but also tends to be preferred by both the retailer and the consumers. Hendershott and Zhang [13] proposed a search model by assuming intermediaries and consumers are heterogeneous. They concluded that all consumers are better off from the upstream firm's entry at the expense of intermediaries, while the net result is an increase in social welfare. Arya [14] proposed a Cournot model to capture the quantitative competition between the manufacturer and the retailer. Their results revealed that the manufacturer's encroachment may benefit the retailer even when encroachment offers no synergies and does not facilitate product differentiation or price discrimination. Dumrongsiri [15] studied a dual-channel supply chain considering channel demand based on price and service quality. They argued that the addition of a direct channel will increase overall profit. The negative side of the entry of the direct channel has also been investigated by other researchers (Bernstein [16]; Ofek [17]).

Since adding a direct channel may lead to channel competition and conflict, a number of researchers have possible mechanisms to coordinate dual-channel supply chains. Tsay and Agrawal [2] and Cattni et al. (2004) provided explicit surveys on channel coordination in dual-channel distribution systems. Tsay and Agrawal [18] examined different ways to adjust manufacturer-reseller relationships observed in industry, e.g., changes in wholesale pricing, paying the reseller a commission for diverting consumers towards the direct channel, and conceding the fulfillment function entirely to the reseller. Boyaci [19] designed a novel two-part compensationcommission contract to coordinate dual-channel conflict, whose terms depend on the retail channel's sales. The coordinating supply contract proposed by Seifert [20] involves joint specification of wholesale price, an endinginventory subsidy, and a transfer payment from the manufacturer's virtual store to the retailer when using excess retail stock. Cai [21] propose a revenue sharing policy to coordinate a dual-channel supply chain. Yan [5] shows that strategic channel integration with profit sharing can effectively reduce channel conflict and improve channel coordination for both parties in the dual-channel system. Yan [22] employs differentiated branding and profit sharing strategies to coordinate a multi-channel manufacturer-retailer supply chain.

Consumer choice in dual-channel context has also been studied by many researchers. A number of recent papers have addressed issues related to consumer choice in mixed channel supply chains. Liang conducted an empirical study to show that in general, consumers prefer traditional retail channel to the directonline channel. By segmenting consumers into service sensitive and price sensitive segments, Rhee and Park [23] demonstrated that hybrid channels using direct online marketing are optimal when customers are similar across segments in their valuations of retailing services. An empirical study conducted by Van den Poel and Leunis [24] showed that Internet offerings with a mix of risk relievers are highly accepted. Chiang [10] exemplified different product categories to show that consumer acceptance of directonline channel is less than that of the conventional channel. Schoenbachler and Gordon [25] proposed a model of multi-channel buyer behavior to help the multi-channel marketer develop a customer-centric view. Reardon and McCorkle [26] expanded Becker's theory of time allocation to consumer choice between distribution channels, and developed a formal consumer model to clarify channel switching behavior. Kumar and Ruan [7] divided consumers into two types: brand loyal and store loyal. They demonstrated that the optimal mixed channel strategy and the role of the direct online channel relies on the level of support that the retailer allocates to the manufacturer's product, in the absence of the direct online channel. Based on their consumer segments, Cai [21] showed that a consistent pricing scheme can effectively alleviate channel conflict by generating more profit for the extant retailer. Chen [27] summed up key factors in choosing between the traditional retailer and the direct channel as: delivery lead time, product availability and retailer inconvenience cost. 


\section{Model Framework}

The basic model framework employed to address relative questions in our research is presented as follows.

\subsection{Consumer Choice and Demand Functions}

In accordance with Kumar and Ruan [7], heterogeneous consumers are assumed to be segmented into brand (or manufacturer) loyal and store (or retailer) loyal. Brand (or manufacturer) loyal consumers only purchase the manufacturer's brand, from either the conventional retailer or the manufacturer directly, whereas store (or retailer) loyal customers only purchase from the retailer, disregarding the brand difference. Market sizes of brand (or manufacturer) loyal and store (or retailer) loyal consumers are denoted by $\alpha_{m}$ and $\alpha_{r}$, respectively. Furthermore, brand (or manufacturer) loyal consumers determine their channel choice according to the corresponding consumer surplus, and this consumer choice is derived from subjective acceptance levels of the direct online channel and objective price differences. In line with Liang, Kacen and Chiang [10], we assume consumers are also heterogeneous in valuation of purchasing the product from the retailer or the manufacturer directly. We denote the product valuation by $v$, and for analytical simplicity, assume it is uniformly distributed within consumer population between 0 and 1, with density 1. A product that is worth $v$ if subject to a real inspection and instant gratification only has the worth of $\theta v, \theta \in(0,1)$ when it is purchased from a direct online channel with virtual inspection and long lead time. It is noted that the value of the parameter $\theta$ is defined as the consumer acceptance of the direct online channel by Chiang [10]. Kacen and Chiang [10] enumerated relative acceptance level of the direct online channel inproduct categories (Table 1).

In the light of the aforementioned description, a schematic representation of consumer choice in dual-channel context is given in Figure 1.

Let $D_{1}$ and $D_{2}$ denote consumer demand of the manufacturer (direct channel) and the traditional retailer, respectively. Let $p_{1}$ and $p_{2}$ be the direct online channel selling price and the reselling channel retelling price to the consumers, respectively. At the same time, $\pi_{m}$ and $\pi_{r}$ are assumed to be corresponding functions for the manufacturer and the retailer. As a benchmark, we first consider a no-encroachment setting, where the manufacturer only sells his product exclusively through the retailer. In this market, consumers only purchase the product when their valuations of the product are in the interval $\left[p_{2}, 1\right]$. Therefore, consumer demand for this product in this context for the conventional retailer is denoted as follows:

$$
D_{2}=\left(\alpha_{r}+\alpha_{m}\right)\left(1-p_{2}\right)
$$

Secondly, we consider the encroachment case in which the manufacturer decides to open a directonline channel to sell its product to consumers, after setting wholesale price and supplying product to the incumbent retailer. In this market, store (or retailer) loyal consumers insist on purchasing the product from the retailer, while brand (or manufacturer) loyal consumers who buy the product through either the retail channel or directonline channel, make their purchasing decision on the basis of available consumer surplus. Moreover, by adding a direct online channel, the manufacturer determines wholesale price $w$ for the retailer, and direct sales price $p_{1}$ for consumers purchasing products through the directonline channel. Meanwhile, the incumbent retailer may update reselling price $p_{2}$ to compete against the encroaching manufacturer. A schematic representation of the mixed distribution channel system is presented in Figure 2.

Since the homogeneous products are sold though the direct online channel at price $p_{1}$ and through the conventional retail channel at price $p_{2}$, for brand (or manufacturer) loyal consumers, the consumer surplus of the two channels are denoted as $\theta v-p_{1}$ and $v-p_{2}$, respectively. All brand (or manufacturer) loyal consumers whose valuation satisfies $\theta v-p_{1} \geq$ would consider purchasing from the manufacturer directly, while brand (or manufacturer) loyal consumers whose valuation satisfies $v-p_{2} \geq 0$ would consider buying from the retailer. Therefore, the decision of channel choice for brand (or manufacturer) loyal consumers is made according to the

Table 1. Consumer acceptance index for online direct channel.

\begin{tabular}{ccccccc}
\hline Category & Book & Shoes & Toothpaste & DVD player & Flowers & Food items \\
\hline Acceptance & 0.904 & 0.769 & 0.886 & 0.787 & 0.792 \\
\hline
\end{tabular}

Note: All product categories have $\theta$ below 1.0 at $1 \%$ significance level. 


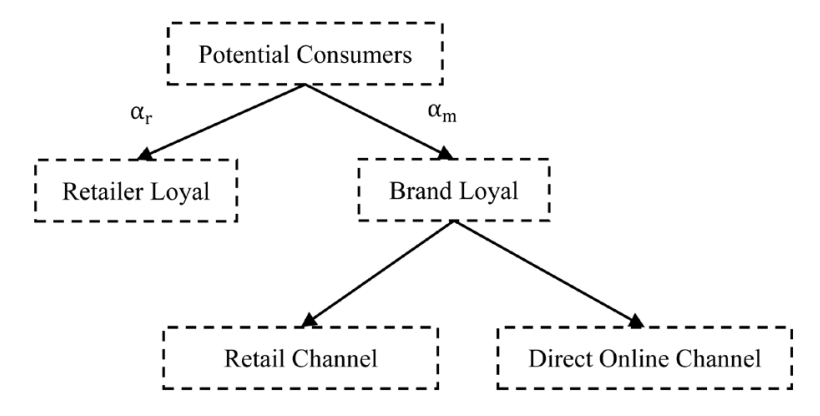

Figure 1. Consumer choice.

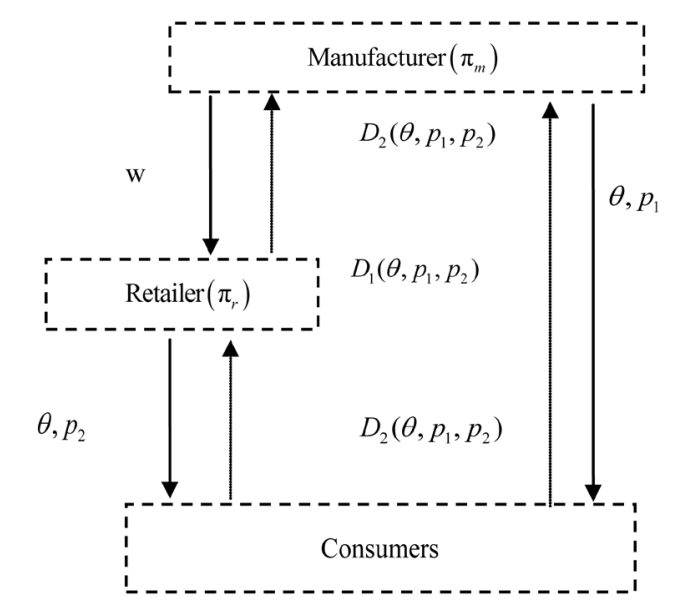

Figure 2. A dual-channel distribution system.

following comparison of $\theta v-p_{1}$ versus $v-p_{2}$. The marginal brand (or manufacturer) loyal consumers whose valuation satisfies $v_{1}=p_{1} / \theta$ are indifferent to purchasing through the direct online channel. Meanwhile, marginal brand (or manufacturer) loyal consumers whose valuation satisfies $v_{2}=p_{2}$ care nothing about buying from the retailer. Consequently, when $v-p_{2}>\theta v-p_{1}$, the retail channel is explicitly preferred to the direct online channel. However, when $v-p_{2}=\theta v-p_{1}$, which equals to $v_{1,2}=\frac{p_{2}-p_{1}}{1-\theta}$, brand (or manufacturer) loyal consumers are indifferent to the choice between the two channels. It is easy to discover that the retailer is likely to be chosen by brand (or manufacturer) loyal consumers, as long as $v>v_{1,2}$.

We can explicitly demonstrate the relationship among $v_{1}, v_{2}$ and $v_{1,2}$. When $v_{1}<v_{2}$, partial order $v_{1}<v_{2}<v_{1,2}$ is easily inferred. In this case, all brand (or manufacturer) loyal consumers with valuation in the interval $\left[v_{1}, v_{1,2}\right]$ may choose to purchase products through the direct online channel, and all those in interval $\left[v_{1,2}, 1\right]$ prefer to buy from the traditional retailer, while all those in interval $\left[0, v_{1}\right]$ will not purchase any product through either channel. Similarly, in the case that $v_{2}<v_{1}$, we can infer $v_{1,2}<v_{2}<v_{1}$. Therefore, no brand (or manufacturer) loyal consumers are willing to purchase products through the direct online channel, and all those whose valuation within interval $\left[v_{2}, 1\right]$ will decide to buy from the retailer. A similar framework was proposed by Chiang [10] to indicate consumer choice.

Based on the aforementioned consumer choice and uniformly distributed valuations of consumers, pricewiselinear demand functions faced by the manufacturer and the retailer after the manufacturer's encroachment can be described as follows,

$$
D_{1}= \begin{cases}\alpha_{m} \frac{\theta p_{2}-p_{1}}{\theta(1-\theta)} & \frac{p_{1}}{\theta} \leq p_{2}, \\ 0 & \frac{p_{1}}{\theta}>p_{2},\end{cases}
$$




$$
D_{2}= \begin{cases}\alpha_{r}\left(1-p_{2}\right)+\alpha_{m}\left(1-\frac{p_{2}-p_{1}}{1-\theta}\right) & \frac{p_{1}}{\theta} \leq p_{2}, \\ \left(\alpha_{r}+\alpha_{m}\right)\left(1-p_{2}\right) & \frac{p_{1}}{\theta}>p_{2} .\end{cases}
$$

Corresponding demand functions in (2) and (3) demonstrate that when the manufacturer sets its direct sale price above a threshold $p_{1} / \theta>p_{2}$, all rational consumers may choose to purchase products from the conventional retailer with the consideration of better price. Since our research seeks to find the impact of consumer choice and addition of the directonline channel on the dual channel supply chain system, we analyze the performance of the co-existing dual-channel supply chain by constraining $p_{1} / \theta \leq p_{2}$.

\subsection{Profit Functions}

For ease of explanation and brevity in analysis part, marginal costs of the manufacturer and the retailer are assumed to be zero, without loss of generality. Therefore, in an expected period, when two channels co-exist, the manufacturer derives its profit from direct online sale revenue and wholesale revenue. Thus, the profit of the manufacturer in a mixed channel context can be expressed as follows:

$$
\pi_{m}=p_{1} D_{1}+w D_{2}
$$

Similarly, the profit formulation for the retailer is as follows:

$$
\pi_{r}=\left(p_{2}-w\right) D
$$

Finally, the total profit of the whole supply chain in a dual-channel circumstance is written as follows:

$$
\pi_{t}=p_{1} D_{1}+p_{2} D_{2}
$$

Define abbreviations and acronyms the first time they are used in the text, even after they have been defined in the abstract. Abbreviations such as IEEE, SI, MKS, CGS, sc, dc, and rms do not have to be defined. Do not use abbreviations in the title or heads unless they are unavoidable.

\section{Analysis}

\subsection{Basic Results}

In this section, we derive optimal closed-form solutions in manufacturer-Stackelberg game, the timing of which is described as follows. First, the manufacturer establishes its wholesale price $(w)$. Note that the wholesale price has to be stipulated to be not higher than the direct online sale price, that is $w \leq p_{1}$, in order to keep the retailer from purchasing through direct online channel or from other arbitrageurs. Second, the retailer chooses its retail price $\left(p_{2}\right)$ in the benchmark setting, while in the dual-channel context, the manufacturer determines its direct sale price $\left(p_{1}\right)$ and the retailer decides its retail price $\left(p_{2}\right)$ simultaneously in a Nash game [28]. We solve the game by backward induction. Similar game configurations have been used in the literature by Chiang [10], Yan [29] [30] and Chun [31]. In what follows, the results for both the non-encroachment and encroachment settings are summarized in Table 2 and Table 3, respectively.

\subsection{Traditional Retail Channel vs. Dual Channel}

In order to examine the effect of consumer choice on profits of the manufacturer, the retailer and the total supply chain, we compare corresponding results in Table 2 and Table 3. One would expect the encroachment to sell directly to end consumers would benefit the upstream manufacturer. In what follows, Proposition 1 reconsiders this conventional wisdom.

Proposition 1. The manufacturer opens a direct online channel if and only if $\theta^{*}=\frac{\alpha_{m}+\alpha_{r}-\sqrt{\left(\alpha_{m}+\alpha_{r}\right) \alpha_{m}}}{\alpha_{r}}<\theta \leq 1$. The manufacturer benefits from the addition of direct online channel because in this case: $\frac{\theta\left(\alpha_{m}+\alpha_{r}\right)\left[2 \alpha_{m}+(1-\theta) \alpha_{r}\right]}{8\left[(1-\theta) \alpha_{r}+\alpha_{m}\right]}-\frac{\alpha_{m}+\alpha_{r}}{8}>0$. 
Table 2. Prices, demand and profits in traditional retail channel.

$\begin{array}{cc}\text { Wholesale price, } w & \frac{1}{2} \\ \text { Traditional channel price, } p & \frac{3}{4} \\ \text { Traditional channel demand, } D & \frac{\alpha_{r}+\alpha_{m}}{4} \\ \text { Manufacturer's profit, } \pi_{m} & \frac{\alpha_{r}+\alpha_{m}}{8} \\ \text { Retailer's profit, } \pi_{r} & \frac{\alpha_{r}+\alpha_{m}}{16} \\ \text { Total profit, } \pi_{t} & \frac{3\left(\alpha_{r}+\alpha_{m}\right)}{16}\end{array}$

Table 3. Prices, demand and profits in a dual-channel distribution system.

$\begin{array}{ccc}3 & \frac{\theta}{2} \\ \text { Wholesale price, } w & \frac{\theta}{2} \\ \text { Traditional channel price, } p_{2} & \frac{3(1-\theta) \alpha_{r}+(3-\theta) \alpha_{m}}{4\left[(1-\theta) \alpha_{r}+\alpha_{m}\right]} \\ \text { Online direct channel demand, } D_{1} & \frac{\left(\alpha_{r}+\alpha_{m}\right) \alpha_{m}}{4\left[(1-\theta) \alpha_{r}+\alpha_{m}\right]} \\ \text { Traditional channel demand, } D_{2} & \frac{\alpha_{r}+\alpha_{m}}{4} \\ \text { Manufacturer's profit, } \pi_{m} & \frac{(1-\theta)\left(\alpha_{r}+\alpha_{m}\right)\left[3 \alpha_{m}+(3-2 \theta) \alpha_{r}\right]}{16\left[(1-\theta) \alpha_{r}+\alpha_{m}\right]} \\ \text { Retailer's profit, } \pi_{r} & \frac{\theta\left(\alpha_{r}+\alpha_{m}\right)\left[2 \alpha_{m}+(1-\theta) \alpha_{r}\right]}{8\left[(1-\theta) \alpha_{r}+\alpha_{m}\right]} \\ \text { Total profit, } \pi_{t} & \frac{\left(\alpha_{r}+\alpha_{m}\right)\left[(3+\theta) \alpha_{m}+(1-\theta) \alpha_{r}\right]}{16\left[(1-\theta) \alpha_{r}+\alpha_{m}\right]}\end{array}$

The rationale is that when the acceptance of direct online channel falls below the threshold $\theta^{*}$, adding a directonline channel to the market may not attract more consumers, thus benefiting the manufacturer. It is noted that $\theta^{*} \rightarrow \frac{1}{2}$ as $\frac{\alpha_{m}}{\alpha_{r}} \rightarrow+\infty, \theta^{*} \rightarrow 1$ as $\frac{\alpha_{m}}{\alpha_{r}} \rightarrow 0$, and $\theta^{*}$ decreases as $\frac{\alpha_{m}}{\alpha_{r}}$ increases. More specifically, this result demonstrates that in the case when almost all or most consumers are brand (or manufacturer) loyal, the manufacturer cannot benefit from encroachment unless the acceptance of direct online channel exceeds $1 / 2$, while in the case when almost all or most consumers are store (or retailer) loyal, the manufacturer can benefit from encroachment if and only if all consumers fully accept the online channel. Furthermore, the more brand (or manufacturer) loyal the consumers are, the more loose constraints there are for acceptance of the direct online channel that can help manufacturer benefit from encroachment. However, the manufacturer would not benefit from adding a direct online channel unless the acceptance of the directonline channel is over $1 / 2$, irrespective of whether the consumers' preference is for brand (or manufacturer) or store (or retailer). 
Next, we investigate the effect of the manufacturer's encroachment on the retailer's profit. The conventional wisdom argues that the increased competition accompanied by the addition of direct online channel will harm the traditional retailer. However, a substantial mass of existing literatures has suggested that the retailer can benefit from the manufacturer's encroachment on the condition that the manufacturer may reduce its preferred wholesale price (Chiang [10]; Arya [14]). Since profit is always the focal point, we compare the retailer's profit in Table 2 with profit in Table 3. Then, Proposition 2 is presented as below.

Proposition 2. Adding a direct online channel can increase the retailer's if and only if $0 \leq \theta \leq \theta^{* *}=\frac{4 \alpha_{r}+3 \alpha_{m}-\sqrt{8 \alpha_{r} \alpha_{m}+9 \alpha_{m}^{2}}}{4 \alpha_{r}}$. The retailer benefits from the manufacturer's encroachment because in this case: $\frac{(1-\theta)\left(\alpha_{m}+\alpha_{r}\right)\left[3 \alpha_{m}+(3-2 \theta) \alpha_{r}\right]}{16\left[(1-\theta) \alpha_{r}+\alpha_{m}\right]}-\frac{\left(\alpha_{r}+\alpha_{m}\right)}{16}>0$.

Recalling Table 2 and Table 3, we notice that $\frac{\theta}{2} \leq \frac{1}{2}, \theta \in[0,1]$. The manufacturer sets a lower wholesale price to counterbalance the traditional retail channel and the additional direct online channel, in order not to reduce the incumbent retailer's essential output. The reduction of the wholesale price implies that the retailer may benefit from the manufacturer's encroachment, when consumers' acceptance of the direct online channel does not exceed the threshold $\theta^{* *}$. Note that a much larger number of on consumers prefer to purchase products from the manufacturer directly when $\theta>\theta^{* *}$, which definitely harms the retailer. Furthermore, similar to Proposition $1, \theta^{*} \rightarrow \frac{2}{3}$ as $\frac{\alpha_{m}}{\alpha_{r}} \rightarrow+\infty, \theta^{* *} \rightarrow 1$ as $\frac{\alpha_{m}}{\alpha_{r}} \rightarrow 0$, and $\theta^{* *}$ increases as $\frac{\alpha_{m}}{\alpha_{r}}$ decreases. The computational results indicate that when brand (or manufacturer) loyal consumers constitute the majority of the total consumers, the retailer can benefit from the manufacturer's entry if and only if acceptance of the direct online channel $\theta$ does not exceed $2 / 3$, while when the majority are store (or retailer) loyal consumers, the retailer can always benefit from the manufacturer's encroachment, regardless of level of the consumers' acceptance of the direct online channel. In addition, the more brand (or manufacturer) loyal the consumers are, the narrower is the interval for acceptance of the direct online channel that benefits the incumbent retailer from the manufacturer's encroachment.

By comparing Proposition 1 with Proposition 2, it is easy to find that $\theta^{*} \leq \theta^{* *}$. Hence, we propose a win-win range by constraining acceptance of the direct online channel to benefit both the manufacturer and the retailer in the following Proposition 3. Yan and Pei [32] presented a similar twin winners' zone where both the manufacturer and the retailer benefit from improved retail services under dual-channel competition.

Proposition 3. Both the manufacturer and the retailer can benefit from addition of the direct online channel when acceptance of direct online channel $\theta$ locates in the interval $\left[\theta^{*}, \theta^{* *}\right]$, where

$$
\theta^{*}=\frac{\alpha_{m}+\alpha_{r}-\sqrt{\left(\alpha_{m}+\alpha_{r}\right) \alpha_{m}}}{\alpha_{r}}, \quad \theta^{* *}=\frac{4 \alpha_{m+} 3 \alpha_{r}-\sqrt{8 \alpha_{r} \alpha_{m}+9 \alpha_{m}^{2}}}{\alpha_{r}} .
$$

The rationale is that when acceptance of the direct online channel $\theta$ locates in interval $\left[\theta^{*}, \theta^{* *}\right]$, on one hand, the manufacturer earns more profit by adding a directonline channel, though he lowers wholesale price for the incumbent retailer. On the other hand, not too many brand (or manufacturer) loyal consumers would accept direct online purchasing, and thus the retailer will benefit by reduced wholesale price. When the value of $\theta$ falls in the interval $\left[0, \theta^{*}\right]$, the lower level of acceptance of the direct online channel indicates that few brand (or manufacturer) loyal consumers prefer to buy from the encroaching manufacturer directly, and thus the encroachment does not increase the manufacturer's profit. Similarly, when the value of $\theta$ falls in interval $\left[\theta^{* *}, 1\right]$, the conventional retailer faces adverse conditions where many brand (or manufacturer) loyal consumers may choose to purchase through the direct online channel Therefore, the direct online channel becomes a serious threat to the conventional retailer, and thus the retailer's profit may be negatively influenced.

We compare the profit of the entire dual-channel supply chain under encroachment and non-encroachment settings according to Table 2 and Table 3, and present the relative Proposition 4 as follows.

Proposition 4. The addition of direct online channel can effectively benefit the whole dual-channel supply 
chain by increasing the total profit when $\theta>\theta^{* * * *}=\frac{2 \alpha_{r}}{2 \alpha_{r}+\alpha_{m}}$. Moreover, in this case, the higher the acceptance level of direct online channel $\theta$ and $\frac{\alpha_{m}}{\alpha_{r}}$ are, the higher is the total profit the dual-channel supply chain earn.

Proposition 4 reveals that the addition of direct online channel would definitely increase the profit of the total dual-channel supply chain when the acceptance level exceeds a threshold $\theta^{* * *}=\frac{2 \alpha_{r}}{2 \alpha_{r}+\alpha_{m}}$. Since the increase is proportional to the acceptance of direct online channel, total profit can increase by as much as $33.3 \%$ when brand (or manufacturer) loyal consumers completely accept the directonline channel $(\theta=1)$, in which case encroachment enables the manufacturer to reduce wholesale price and serve end consumers directly, thereby limiting losses from double marginalization by using a direct online channel. Furthermore, since the total supply chain profit increases with increase of acceptance level of the direct online channel $\theta$, the larger $\frac{\alpha_{m}}{\alpha_{r}}$ indicates more brand (or manufacturer) loyal consumers in the market, and thus the manufacturer's encroachment leads to more profit for the whole supply chain.

\subsection{Channel Integration}

In recent years, integration of direct online channel and traditional retail channel has been widely used in many industries. For instance, some companies allow consumers to search desired products online and place an order, and then arrange for order picking up at a local conventional retail channel. Channel integration aims to streamline different channel activities and information flow to achieve mutual benefits to all involved members. The manifold advantages of channel integration include reduced transaction costs, improved inventory management, an barriers to new market entrant and reduced loss of business opportunities from delayed delivery, etc. (www.icmrindia.org). In real business world, Wal-Mart, Home Depot, Electronics Boutique and Macy's have successfully synchronized pricing strategies and operations across dual-channel for channel integration (Yan, [5]).

When the direct online channel and conventional retail channel are integrated, unified and centralized price solutions are derived from maximizing the total profit of the whole distribution system, which is described in (6). The results are summarized in the following Table 4.

It is noted that zero demand of direct online channel suggests that the integrated system prefers to extract higher margin through the conventional retail channel, thereby improving total channel performance. Channel integration can effectively alleviate the problem of double marginalization resulting from channel competition and channel conflict (Yan, [5]). Hereafter, the superscript "I" and "N" denote variables under channel integration and non-integration, respectively. The following Proposition 5 characterizes the effect of channel integration.

Proposition 5. Thetotal profit of an integrated system $\pi_{t}^{I}$ is more than the total profit of a non-integrated system $\pi_{t}^{N}$. Moreover, the net augment increases as the acceptance of direct online channel $\theta$ and $\alpha_{m} / \alpha_{r}$ decrease.

Table 4. Prices, demand and profits in an integrated distribution system.

$\begin{array}{ccc}\text { Online direct channel price, } p_{1} & \frac{\theta}{2} \\ \text { Traditional channel price, } p_{2} & \frac{1}{2} \\ \text { Online direct channel demand, } D_{1} & \mathbf{0} \\ \text { Traditional channel demand, } D_{2} & \frac{\alpha_{r}+\alpha_{m}}{2} \\ \text { Total profit, } \pi_{t} & \frac{\alpha_{r}+\alpha_{m}}{4}\end{array}$


Proposition 5 reveals the fact that channel integration can definitely benefit the dual-channel supply chain, and the larger is the acceptance of direct online channel $\theta$ and $\frac{\alpha_{m}}{\alpha_{r}}$, the higher is the extra-profit derived from channel integration. Since zero demand of direct online channel indicates that the integrated system can extract more profit from the traditional retailer, and reduction of acceptance of direct online channel $\theta$ and $\frac{\alpha_{m}}{\alpha_{r}}$ imply that much more consumers will purchase through conventional retail channel. Finally, the integrated system absolutely benefits from the decrease of acceptance of direct online channel $\theta$ and $\frac{\alpha_{m}}{\alpha_{r}}$.

\section{Conclusions and Managerial Implications}

The contributions of our work are both theoretical and practical in nature. In today's business environment, with the rapid growth of e-business and third-party logistics companies, such as Federal Express and United Parcel Services, many manufacturers have started opening new direct online channels to sell directly to consumers. Since the manufacturer's encroachment will definitely induce channel competition and conflict, it is of significant importance to develop some mechanisms of cooperation between the manufacturer and the incumbent retailer. Furthermore, in marketing area, consumer choice is of great interest to be studied. For instance, consumer loyalty and acceptance of the direct online channel has been explicitly explored (Chiang [10]; Kumar and Ruan). In this work, we have demonstrated that direct online channel is not necessarily detrimental to the incumbent retailer. A win-win zone related to consumer choice and acceptance of the direct online channel is proposed, where both the manufacturer and the retailer can benefit from the encroachment.

There are some limitations in our analysis. First, we assume all information is known to the manufacturer and the retailer. However, in reality, information could be private, incomplete and asymmetric. Recently, information sharing between the manufacturer and the retailer has received great interest from many multi-channel manufacturers, such as Hewlett \& Packard, Dell Computer, Sony, Mattel and Estee Lauder (Yan and Pei, [32]). Therefore, information sharing policy can be employed as a feature of the coordination scheme in future studies. Second, the formulation of our demand functions revolves around consumer surplus. While a consistent pricing policy limits employment of these demand functions, it is of significant interest to discover other forms of demand function in future research, such as the utility function employed by Ingene and Parry [33] and Cai [21].

\section{References}

[1] Anonymous (1999) Levi’s to Quit Selling Online. San Francisco Examiner.

[2] Seifert, R.W., Thonemann, U.W., et al. (2006) Integrating Direct and Indirect Sales Channels under Decentralized Decision-Making. International Journal of Production Economics, 103, 209-229. http://dx.doi.org/10.1016/j.ijpe.2005.06.006

[3] Berger, P.D., Lee, J., et al. (2006) Optimal Cooperative Advertising Integration Strategy for Organizations Adding a Direct Online Channel. The Journal of the Operational Research Society, 57, 920-927. http://dx.doi.org/10.1057/palgrave.jors.2602069

[4] Yan, R. (2010) Product Brand Differentiation and Dual-Channel Store Performances of a Multi-Channel Retailer. European Journal of Marketing, 44, 672-692. http://dx.doi.org/10.1108/03090561011032324

[5] Yan, R., Wang, J., et al. (2010) Channel Integration and Profit Sharing in the Dynamics of Multi-Channel Firms. Journal of Retailing and Consumer Services, 17, 430-440. http://dx.doi.org/10.1016/j.jretconser.2010.04.004

[6] Lee, H.L., Padmanabhan, V. and Whang, S. (1997) Information Distortion in a Supply Chain: The Bullwhip Effect. Management Science, 43, 546-558. http://dx.doi.org/10.1287/mnsc.43.4.546

[7] Kumar, N. and Ruan, R. (2006) On Manufacturers Complementing the Traditional Retail Channel with a Direct Online Channel. Quantitative Marketing and Economics, 4, 289-323. http://dx.doi.org/10.1007/s11129-005-9003-8

[8] Business 2.0 (2000) 501 Blues. January, 53-56.

[9] Cai, G., Zhang, Z.G., et al. (2009) Game Theoretical Perspectives on Dual-Channel Supply Chain Competition with Price Discounts and Pricing Schemes. International Journal of Production Economics, 117, 80-96. http://dx.doi.org/10.1016/j.ijpe.2008.08.053

[10] Chiang, W.-Y.K., Chhajed, D., et al. (2003) Direct Marketing, Indirect Profits: A Strategic Analysis of Dual-Channel 
Supply-Chain Design. Management Science, 49, 1-20. http://dx.doi.org/10.1287/mnsc.49.1.1.12749

[11] Cattani, K.D., Gilland, W.G. and Swaminathan, J.M. (2004) Coornating Traditional and Internet Supply Chains. Kluwer Academic Publishers, Boston, 643-677.

[12] Cattani, K.D., Gilland, W.G. and Swaminathan, J.M. (2006) Boiling Frogs: Pricing Strategies for a Manufacturer Adding a Direct Channel That Competes with the Traditional Channel. Production and Operations Management, 15, 4056.

[13] Hendershott, T. and Zhang, J. (2006) A Model of Direct and Intermediated Sales. Journal of Economics \& Management Strategy, 15, 279-316. http://dx.doi.org/10.1111/j.1530-9134.2006.00101.x

[14] Arya, A., Mittendorf, B., et al. (2007) The Bright Side of Supplier Encroachment. Marketing Science, 26, 651-659. http://dx.doi.org/10.1287/mksc.1070.0280

[15] Dumrongsiri, A., Fan, M., et al. (2008) A Supply Chain Model with Direct and Retail Channels. European Journal of Operational Research, 187, 691-718. http://dx.doi.org/10.1016/j.ejor.2006.05.044

[16] Bernstein, F., Song, J.-S., et al. (2008) Bricks-and-Mortar vs. Clicks-and-Mortar: An Equilibrium Analysis. European Journal of Operational Research, 187, 671-690. http://dx.doi.org/10.1016/j.ejor.2006.04.047

[17] Ofek, E., Katona, Z., et al. (2010) Bricks and Clicks: The Impact of Product Returns on the Strategies of Multichannel Retailers. Marketing Science, 1, 42-60.

[18] Tsay, A.A. and Agrawal, N. (2004) Channel Conflict and Coordination in the E-Commerce Age. Production and Operations Management, 13, 93-110. http://dx.doi.org/10.1111/j.1937-5956.2004.tb00147.x

[19] Boyaci, T. (2005) Competitive Stocking and Coordination in a Multiple-Channel Distribution System. IIE Transactions, 37, 407-427. http://dx.doi.org/10.1080/07408170590885594

[20] Seifert, R.W., Thonemann, U.W., et al. (2006) Integrating Direct and Indirect Sales Channels under Decentralized Decision-Making. International Journal of Production Economics, 103, 209-229. http://dx.doi.org/10.1016/j.ijpe.2005.06.006

[21] Cai, G. (2010) Channel Selection and Coordination in Dual-Channel Supply Chains. Journal of Retailing, 86, 22-36. http://dx.doi.org/10.1016/j.jretai.2009.11.002

[22] Yan, R., Guo, P., et al. (2011) Product Distribution and Coordination Strategies in a Multi-Channel Context. Journal of Retailing and Consumer Services, 18, 19-26. http://dx.doi.org/10.1016/j.jretconser.2010.09.001

[23] Rhee, B. and Park, S. (1999) Online Store as a New Direct Channel and Emerging Hybrid Channel System. Working Paper, Hong Kong University of Science and Technology, Clear Water Bay.

[24] Van den Poel, D. and Leunis, J. (1999) Consumer Acceptance of the Internet as a Channel of Distribution. Journal of Business Research, 45, 249-256. http://dx.doi.org/10.1016/S0148-2963(97)00236-1

[25] Schoenbachler, D.D. and Gordon, G.L. (2002) Multi-Channel Shopping: Understanding What Drives Channel Choice. The Journal of Consumer Marketing, 19, 42-53. http://dx.doi.org/10.1108/07363760210414943

[26] Reardon, J. and McCorkle, D.E. (2002) A Consumer Model for Channel Switching Behavior. International Journal of Retail \& Distribution Management, 30, 179-185. http://dx.doi.org/10.1108/09590550210423654

[27] Chen, K.-Y., Kaya, M., et al. (2008) Dual Sales Channel Management with Service Competition. Manufacturing Service Operations Management, 10, 654-675. http://dx.doi.org/10.1287/msom.1070.0177

[28] Nash Jr., J.F. (1950) The Bargaining Problem. Econometrica, 18, 155-162. http://dx.doi.org/10.2307/1907266

[29] Yan, R. (2008) Profit Sharing and Firm Performance in the Manufacturer-Retailer Dual-Channel Supply Chain. Electronic Commerce Research, 8, 155-172. http://dx.doi.org/10.1007/s10660-008-9020-2

[30] Yan, R. (2011) Managing Channel Coordination in a Multi-Channel Manufacturer-Retailer Supply Chain. Industrial Marketing Management, 40, 636-642.

[31] Chun, S.-H., Rhee, B.-D., et al. (2011) Emerging Dual Channel System and Manufacturer's Direct Retail Channel Strategy. International Review of Economics \& Finance, 4, 812-825.

[32] Yan, R. and Pei, Z. (2009) Retail Services and Firm Profit in a Dual-Channel Market. Journal of Retailing and Consumer Services, 16, 306-314. http://dx.doi.org/10.1016/j.jretconser.2009.02.006

[33] Ingene, C. and Parry, M. (2007) Bilateralmonopoly, Identical Competitors/Distributors, and Game-Theoretic Analyses of Distribution Channels. Journal of the Academy of Marketing Science, 35, 586-602. http://dx.doi.org/10.1007/s11747-006-0006-0 
Scientific Research Publishing (SCIRP) is one of the largest Open Access journal publishers. It is currently publishing more than 200 open access, online, peer-reviewed journals covering a wide range of academic disciplines. SCIRP serves the worldwide academic communities and contributes to the progress and application of science with its publication.

Other selected journals from SCIRP are listed as below. Submit your manuscript to us via either submit@scirp.org or Online Submission Portal.
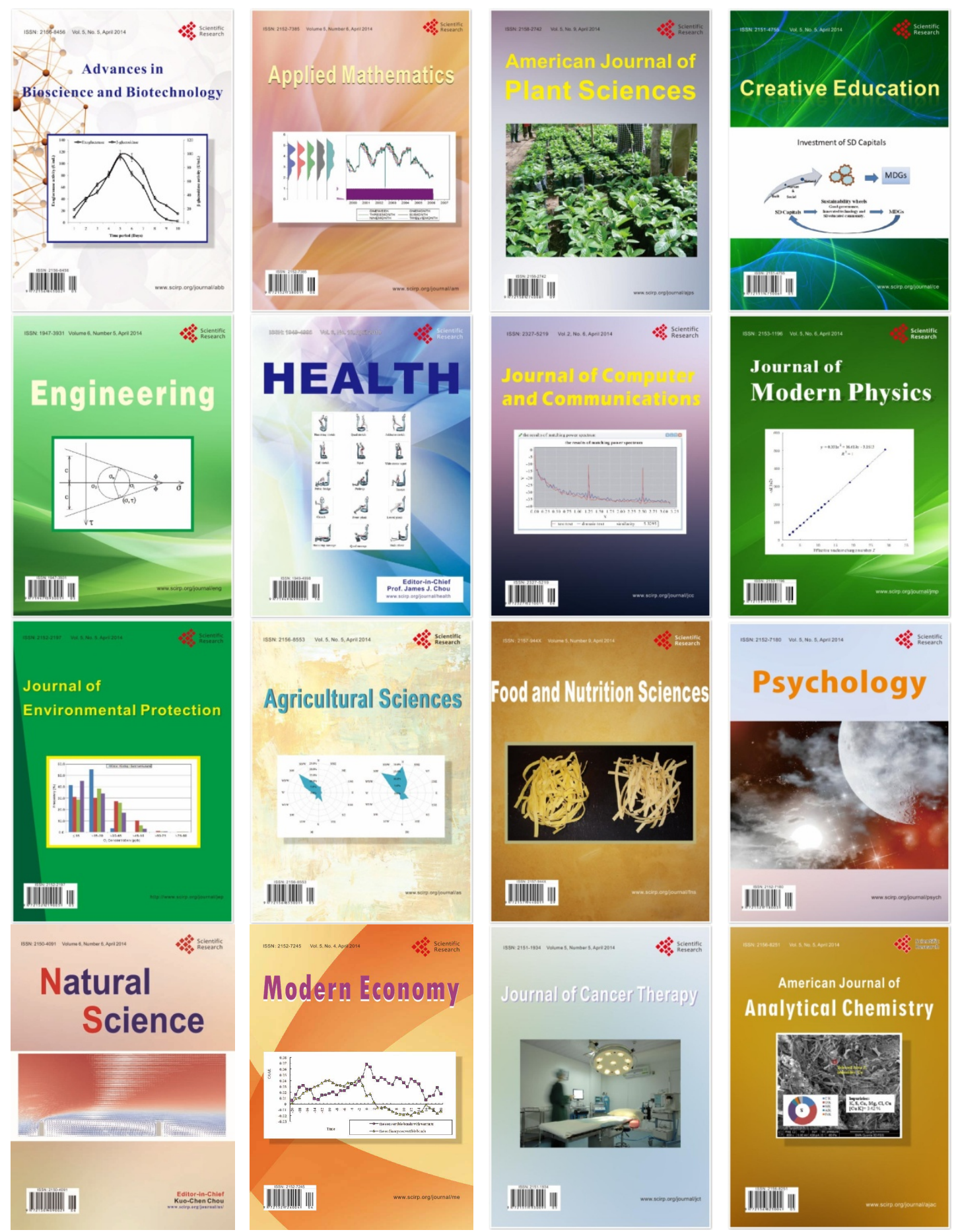